\title{
Trabalho e gênero: permanências e desafios
}

\author{
Magda de Almeida Neves
}

\begin{abstract}
R esumo: O rápido processo de mudanças na economia global nos últimos anos e a reestnuturação produtiva reconfiguraram as relaçães de gênero no trabalho. A entrada cada vez maior do contingente feminino no mercado de trabalho, além de dar visibilidade às relações que se engendram na esfera privada, apresenta um conjunto de novas experiências vivenciadas pelas mulheres no local de trabalho e no contexto mais amplo da própria sociedade. Nestes últimos anos a dinâmica flexível do processo produtivo acarretou o crescimento significativo do trabalho informal, em um processo caracterizado pela sua heterogeneidade e também pela forma sistêmica de interação entre o setor formal e o informal. O dbjetivo db presente artigo é analisar o trabalho em domicílio realizadb por mulheres para a indústria de confeoção numa cidade de porte médio em Minas Gerais. O enfraquecimento da regulação do trabalho e dos direitos sociais possibilitam a multiplicação dessas atividades precarizadas, gerandb flexibilização db contrato de trabalho, cas condições de trabalhor da jomada de trabalho e uma extensão/interação entre espaço privadb/dbméstico e espaço econâmico/produtivo.
\end{abstract}

Palavras-chave: trabalho feminino; industria de confecção; flexibilização do trabalho.

I - Relações de gênero e mercado de trabalho

0 rápido processo de mudanças da economia global nos últimos anos e a reeestruturação produtiva que vem tendo forte impacto no mundo do trabalho têm suscitado inúmeras indagações, para estudiosos e pesquisadores, sobre as conseqüências que esses fenômenos trazem para a sociedade e para os homens e mul heres trabal hadores (Neves, 1998).

A s conquistas trabal histas que asseguraram em muitos países, ao longo do século $X X$, um conjunto de direitos, a partir das inovações tecnológicas e, também, de novos métodos de gerenciamento da mão-de-obra e do processo de trabalho, passaram por acentuadas modificações. N ovas formas mais flexíveis de contratação e uso da força de trabal ho foram estabelecidas, como o trabalho temporário, o trabalho

\footnotetext{
* Doutora em Sociologia pela USP e professora do Progra-
} ma de Pós-graduação em Ciências Sociais da PUC-M inas. em tempo parcial, a terceirização, enfim, outras formas de precarização das condições e de relações de trabal ho que tiveram impacto imediato nos direitos dos trabal hadores, provocando perda acentuada dos direitos conquistados.

Diversas pesquisas realizadas na A mérica L atina demonstram que a participação feminina no mercado de trabal ho, no contexto dos processos de globalização e ajuste estrutural, é bastante heterogênea, estando presente nas indústrias, mas com crescimento constante no setor de serviços e comércio. A inserção das mulheres nas indústrias, muitas vezes, ocorre na forma de "inserção excluída", em que estas ocupam funções menos qualificadas e com menor oportunidade de mobilidade ocupacional. A lém disso, os processos de desintegração vertical das grandes firmas têm significado uma forte assi metria de poder entre as empresas que compõem a cadeia produtiva, constituída por relações de subcontratação, fundada em uma lógica de diminuição de custos, e por forte precarização das 
condições de trabalho, com presença significativa das mulheres. 0 que as pesquisas apontam é que o perfil do trabal hador coletivo, integrante desse novo processo de trabalho produtivo, é fortemente segmentado, em termos de suas condições objetivas e subjetivas, marcado fortemente pelas relações de gênero, raciais e de gerações.

0 impacto da reestruturação produtiva na vida das mulheres trabal hadoras, não só na vida produtiva, mas, principal mente, na relação entre produção e reprodução, vem suscitando inúmeros questionamentos, tanto para as pesquisadoras como para os diferentes movimentos sociais.

0 conceito de relações de gênero permitiu avançar na compreensão da complexidade dessa relação, possi bilitando desnatural izar uma série de fenômenos históricos e superar a abordagem limitadora do aparato biológico para explicar as diferenças masculinas e femininas. V ários estudos já apontaram que as relações entre homens e mulheres atravessam a sociedade e articulam-se com o conjunto das relações sociais, podendo ser modificadas historicamente. Evidentemente que a entrada cada vez maior do contingente feminino no mercado de trabal ho, além de dar visibilidade às relações que se engendram na esfera privada, apresenta um conjunto de novas experiências vivenciadas pelas mulheres no local de trabal ho e no contexto mais amplo da própria sociedade.

Desde a década de 1970, vem crescendo consideravelmente a presença feminina no mercado de trabalho.A nálise da Fundação Carlos Chagas, ao verificar o comportamento da força de trabal ho feminina no B rasil, salienta a intensidade e a constância de seu crescimento, tendo, entre 1976 a 2002, um acréscimo de 25 milhões de trabalhadoras. De 1992 a 2002 , verifica-se que a PEA feminina passou de 28 milhões para 36,5 milhões, aumentando a taxa da atividade feminina de $47 \%$ para $50,3 \%$ e a percentagem de mulheres no conjunto de trabalhadores de $39,6 \%$ para $42,5 \%$. Se, em 1976, 28 em 100 mulheres trabal havam, no novo milênio metade das mulheres trabalha ou procura empregos (FCC, 1998).

Nos últimos anos, um dos fatores que contribuíram para dar maior visibilidade ao trabalho feminino realizado na sociedade foi provocado pela mudança da metodologia utilizada pelo IBGE, incluindo, entre outras, as atividades para autoconsumo e a produção familiar, que sempre foram realizadas por mulheres. Entretanto, apesar das mudanças, o trabalho doméstico executado também pelas mulheres, e fundamental para a reprodução da sociedade, continua a ser classificado como inatividade econômica.

No mercado formal de trabalho, ainda de acordo com o banco de dados da Fundação Carlos Chagas, apesar da forte presença das mulheres, a estrutura desses empregos não se altera, demonstrando que a presença feminina ainda é mais numerosa em determinados setores da atividade econômica. Os empregos femininos nos serviços públicos duplicaram nos últimos 17 anos; na educação e na saúde, em 1985, perfaziam $16 \%$ dos empregos femininos e, em 2002, aumentaram para $32 \%$.

No que diz respeito à qualidade do trabal ho, em 2002, percentual expressivo das mulheres, $34 \%$, quando comparado ao dos homens (9\%), ocupava posições mais vulneráveis, como a inserção maior no trabal ho doméstico, trabalho não-remunerado, trabalho para o consumo próprio ou do grupo familiar. Dado importante a ser ressaltado é que $75 \%$ das trabalhadoras domésticas não tinham carteira assinada nesse mesmo ano e $94 \%$ recebiam dois salários mínimos. Outra evidência da fragilidade do trabal ho feminino, a partir do local de trabal ho no qual desempenham atividades, fica demonstrada pelo percentual de mulheres, $75 \%$, em 2002 , que trabal havam por conta própria ou no domicílio.

A inda de acordo com dados da Fundação Carlos Chagas, fator de significativa relevância, nos últimos anos, tem sido o aumento da escolaridade feminina em relação à dos homens. Se compararmos a trajetória de nove anos de estudo no ensino médio e universitário, constatase que, em 1999, 23\% dos homens, em relação a $27 \%$ mulheres, tinham conseguido al cançar esse patamar, enquanto, em 2002, o percentual das mulheres superou o dos homens, $31 \%$ em relação a $28 \%$. Importante incorporar nessa análise a matrícula das mulheres em 2002, no ensino médio (54\%) e ingressas no vestibular (56\%). Entretanto, a presença das mulheres 
ainda permanece mais numerosa nos cursos superiores da área da educação (75\%), humanidades e artes (63\%) e saúde e bem-estar $(72 \%)$, formando, dessa maneira, alguns guetos educacionais. Os homens superam as mulheres nas ciências, computação, agricultura e veterinária, engenharia de produção e construção.

A pesar do aumento da escolaridade, continua a persistir a desigual dade dos rendimentos femininos diante dos masculinos. A s mulheres ganham menos que os homens, independentemente do setor de atividades em que estão inseridas. Por exemplo, no setor da educação, saúde e serviços, com presença predominantemente feminina, existe uma maior proporção de homens $(30 \%)$ versus de mulheres $(15 \%)$, com rendimentos superiores a cinco salários mínimos. O utro dado importante, e que chama atenção na análise feita pelas pesquisadoras da Fundação Carlos Chagas, é que o fato de ter maior escolaridade conseqüentemente implicaria maior rendimento, o que se confirma para os homens e não tanto para as mulheres. Comparando 15 anos ou mais de escolaridade ou a obtenção de um diploma de curso superior, verifica-se que $42 \%$ dos homens, em relação a $15 \%$ das mulheres, com o mesmo perfil, têm rendimentos superiores a dez salários mínimos. Finalmente, em todas as carreiras, persiste 0 diferencial de rendimentos entre os sexos. Segundo o IBGE, em 2002, o rendimento médio da população ocupada era de 636,50 reais , mas, separando por sexo, verifica-se que o rendimento médio dos homens era de 719,90 e, já entre as mulheres, de 505,90 reais.

Pesquisa realizada pelo Instituto Ethos (2003), focalizando as 500 maiores empresas do Brasil, com o objetivo de analisar o perfil social, racial e de gênero, e suas ações afirmativas, apresenta alguns aspectos importantes a serem ressaltados neste artigo.

A pirâmide organizacional nas grandes organizações empresariais é extremamente excludente para as mulheres. A pesquisa revelou que só $9 \%$ das mulheres ocupam cargos de direção, $18 \%$ são gerentes, $28 \%$ supervisoras e $35 \%$ funcionárias. M aior discriminação ocorre com as mulheres negras: somente $1 \%$ ocupam cargos de gerência e $0,1 \%$, cargos executivos. Esse dado demonstra uma forte segmentação no mercado de trabalho e dupla discriminação de sexo e cor, configurando uma realidade na qual as trabal hadoras negras são as mais pobres. O utro aspecto relevante apontado pela pesquisa diz respeito aos rendimentos. Quanto maior 0 salário pago pelas grandes empresas, menor a presença feminina.Na faixa acima dos que ganham 30 salários mínimos, as mulheres são minoria.

Outro dado importante, e que a pesquisa da F undação Carlos Chagas também salientou, é a mudança do perfil feminino no mercado de trabal ho. Se, na década de 1970, o ingresso no mercado de trabalho era de mulheres jovens e solteiras, nos últimos anos, o que se tem observado é a entrada cada vez maior de mulheres em idades mais elevadas, casadas e que permanecem trabalhando. Conseqüência da permanência da mulher no mercado de trabalho reflete-se na queda da taxa de fecundidade: 5,8 filhos em 1970 para 2,4 por mulher em 2002.

A specto ressal tado neste estudo é o fato de que são poucas as organizações com políticas claras de promoção de eqüi dade de gênero, com programas para a redução da desigualdade salarial e a capacitação profissional para qualificação das mulheres.

Salientar alguns aspectos da permanência e das mudanças da participação feminina no mundo do trabalho torna-se importante para 0 entendimento das relações de gênero no contexto mais amplo da sociedade. Compreender a forma como as mulheres se incorporam e são incorporadas no mercado de trabal ho significa entender as construções históricas e culturais na dinâmica das relações sociais entre homens e mul heres e os significados e as representações do feminino e do masculino. As relações de gênero ocorrem nos vários espaços de interação social, como a família, os locais de trabal ho, as diferentes instituições e o seus significados conformam subjetividades e identidades. Dessa maneira, as discriminações estabelecidas no mundo do trabal ho entre homens e mulheres são fortemente marcadas por val ores culturais, que transformam as diferenças em relações de desigualdade e de preconceito no que diz respeito às mulheres. 
II - O trabalho feminino na indústria de confecção

N este cenário de economia globalizada e de forte competição, a indústria de vestiário foi duramente atingida pela concorrência dos preços baixos. Como conseqüência, ocorreu uma intensa reestruturação do setor, com flexibilização das relações de trabalho. As empresas descentralizaram suas atividades produtivas em diferentes espaços territoriais e, na maioria das vezes, incorporam o trabal ho das mulheres em domicílio. N esse contexto, as mulheres trabaIham sem nenhuma proteção trabalhista, sem carteira assinada, nem jornada de trabal ho definida e muitas vezes incorporando a família nas tarefas produtivas, inclusive os filhos. $A$ marca dessa forma de inserção no mercado de trabal ho caracteriza-se pela informalidade e pela precarização das atividades.

E $m$ pesquisa realizada em uma cidade de porte médio no interior de M inas Gerais, essa tendência foi comprovada (Neves e Pedrosa, 2005). A informalidade, fenômeno de caráter estrutural no contexto da reestruturação produtiva, encontra-se em plena expansão na indústria de confecção dessa cidade, através do trabalho domiciliar das costureiras. Focada na desconcentração, flexibilidade e redução de custos, a marca da reestruturação na indústria de confecção tem sido a terceirização, o que acompanha as tendências da reestruturação produtiva no Brasil.

Os trabal hadores diretos das empresas que estão no topo têm direitos sociais que vão se reduzindo ao longo das cadeias produtivas que se formam nos processos de terceirização, caracterizado na sua ponta, na maioria das vezes, pel o trabal ho desprotegido socialmente. $V$ ários estudos a este respeito (A bramo, 1998; Hirata, 1998; N eves, 2000) têm apontado para o aumento da participação das mulheres, cujo trabalho têm se concentrado na ponta da cadeia, com acentuada precariedade.

A ausência do reconhecimento do vínculo empregatício tem sido um dos motivos da expansão dessa modalidade de trabalho no contexto da reestruturação produtiva, cujas características são: a) sonegação dos benefícios e direitos assegurados pela legislação aos trabalhadores; b) intensificação do trabalho e extensão da jornada para que possam cumprir os prazos contratados; d) irregularidade dos rendimentos devido à demanda variável de trabalho; e) pequena ou nula capacidade de negociação com os contratantes em decorrência da dispersão e inexistência de contatos entre os trabal hadores contratados, tornando difícil ou inviável qualquer forma de organização e atuação col etiva; f) difícil registro fidedigno de sua magnitude devido a seu caráter oculto ou invisível; g) utilização predominantemente de mão-de-obra-feminina. (Silva, 2004, p. 276)

A s estratégias de reestruturação, fundadas no trabal ho domiciliar informal, têm encontrado ressonância entre as mulheres, diante da obrigatoriedade das tarefas domésticas e 0 cuidado com os filhos.

$\mathrm{Na}$ indústria de confecção, a adoção do processo de terceirização faz parte da reestruturação do setor, buscando torná-lo mais competitivo, em face das dificuldades com a concorrência estrangeira, após a abertura comercial dos anos 1990. As formas de reestruturação na indústria da confecção caracterizam-se mais pela descentralização e pela flexibilização da produção do que pela incorporação de novas tecnologias, cujo objetivo primordial é a redução dos custos, especial mente os encargos sociais.

Embora esse segmento utilize predominantemente 0 trabalho feminino, algumas de suas tarefas são tradicionalmente realizadas por homens. Em geral, as principais etapas do processo produtivo são: criação de modelos, elaboração de moldes, infesto, ${ }^{1}$ corte, costura, estamparia e acabamento. A criação de modelos e a elaboração de moldes envolvem poucos trabalhadores e exigem maior grau de qualificação, não havendo distinções de gênero na execução dessas tarefas. 0 infesto e o corte são realizados por homens e também envolvem poucos trabal hadores. A costura, que representa aproximadamente $80 \%$ da força de trabalho

1. Infesto refere-se à preparação do tecido para o corte, envolvendo a colocação de várias camadas desse material sobre uma grande mesa. 
utilizada em todo o processo produtivo, é real izada por mulheres e é esta etapa que está sendo terceirizada, juntamente com o acabamento e a estamparia.

A breu e Sorj (1993), ao estudarem o trabaIho em domicílio no contexto da indústria de confecção do Rio de J aneiro, apontam alguns resultados que podem ser paradigmáticos nesse tipo de trabalho. Para essas autoras, o trabal ho real izado no domicílio pelas costureiras terceirizadas está imbricado no papel que a mulher desempenha como mãe, esposa e dona de casa. $N$ ão existe uma separação entre o tempo de trabal ho dedicado às exigências do mercado de confecção e o tempo das tarefas domésticas, no espaço privado. Dessa maneira, não ocorre uma interrupção da jornada de trabalho, pelo contrário, ela é contínua nesse espaço, onde diferentes tarefas são realizadas.

0 trabal ho terceirizado, domiciliar e informal está sendo adotado pela indústria de confecção na cidade pesquisada, como estratégia de reestruturação, visando à redução de custos, o que vem sendo apontado na literatura como uma tendência geral desse segmento no Brasil. A formação de cadeias a partir da desconcentração produtiva na indústria da confecção não elimina as características tayloristas em seu processo de trabalho. Permanece a rígida divisão do trabal ho, a especialização e a repetição de tarefas e a pouca qual ificação do trabaIhador em quase todas as etapas da produção, com exceção da parte de criação. A concepção do produto que se realiza através da criação de modelos, juntamente com os moldes, o infesto e o corte, continua sendo realizada diretamente pela maior parte das empresas. Os moldes são terceirizados somente quando se trata de produção padronizada, a exemplo de moldes de camisas masculinas, que são elaborados por sistemas computadorizados e adquiridos em São Paulo. A s etapas da produção que estão sendo terceirizadas referem-se à estamparia, ao acabamento e à costura, sendo caracterizadas como repetitivas. Nesse sentido, o taylorismo é mantido ao longo da cadeia produtiva, separando-se 0 processo de concepção no topo e a execução nas demais unidades.

0 trabalho de costura e acabamento, quando terceirizado, é realizado por facções. $\mathrm{Na}$ indústria da confecção, facção refere-se ao trabalho informal e precário de costureiras domiciliares. Por ser informal, não se tem o exato número de facções presentes na indústria da confecção da cidade. U ma pesquisa realizada pelo Instituto Centro de Capacitação e A poio ao Empreendedor (Iccape), em 2000, estimou seu número em 1,5 mil unidades.

No presente estudo, optou-se por uma análise qual itativa do trabal ho em domicílio das costurei ras, mediante a realização de entrevistas estruturadas com um número de dez faccionistas escol hidas al eatoriamente na cidade. A análise dos resultados é apresentada a seguir.

Embora seu trabal ho seja discreto e silencioso, realizado na privacidade de suas casas, as faccionistas podem ser localizadas com certa facilidade, na periferia da cidade, em bairros cujos moradores são de baixa renda, sendo comum encontrar uma ou duas costureiras em um único quarteirão. Verificou-se, durante 0 levantamento de dados, um certo receio no fornecimento das informações, especialmente quando indagadas sobre o número de pessoas que trabalham, o que pareceu um temor pela fiscal ização tributária.

As costureiras faccionistas, como já ficou evidenciado, são mulheres. A presentam em comum o fato de serem casadas, terem filhos e al gumas até netos, e suas idades variam entre 30 e 50 anos. Dentre as entrevistadas, apenas uma permanecia no estado civil de solteira e não tinha filhos. Nenhuma das costureiras entrevistadas concluiu o ensino fundamental, sendo trabal hadoras com baixa escolaridade, o que evidencia duas formas de exclusão que se relacionam: a exclusão educacional e a de direitos previstos na legislação trabal hista.

$\mathrm{N}$ ão dá para ganhar muito, mas sei que na minha idade e com a baixa escolaridade que possuo não encontro nada mel hor. (Entrevista, costureira 10)

Elas possuem entre três e cinco máquinas de costura; al gumas costurei ras afirmaram que, nos períodos de maior intensidade de trabal ho, o marido e os filhos colaboram no trabal ho. A lém da família, algumas relataram que, em épocas de pico, nos períodos que antecedem o inverno 
e o final de ano, subcontratam outras companheiras, sem qualquer registro de carteira de trabalho, caracterizando o que tem sido chamado de quarteirização.

No final do ano, quando o serviço aperta, costumo chamar algumas amigas para trabal har comigo. A ssim todos temos um $\mathrm{N}$ atal feliz. (Entrevista, costureira 8)

Não trabal ho 0 ano todo, mas no final do ano, quando o serviço aperta, contrato uma vizinha para me ajudar na costura e col oco meu marido e filhos para arrematar as peças. (Entrevista, costureira 1)

Essas características do trabal ho domiciliar apontam outras duas situações graves. A primeira refere-se ao envolvimento dos filhos no trabalho, indicando a possibilidade de utilização do trabalho infantil, que implica prejuízos à infância e à educação escolar. A segunda situação grave refere-se à sazonal idade do trabal ho, que gera insegurança quanto à renda e à própria sobrevivência, fazendo com que essas trabal hadoras tenham de viver do que ganham a cada dia, sem maiores projetos. Quando indagadas sobre a renda, quase todas as entrevistadas tiveram dificuldades para responder:

$\mathrm{N}$ ão sei fal ar quanto ganho, porque as pessoas me pagam picado e então eu vou usando 0 dinheiro para pagar as despesas e aí perco 0 controle. (Entrevista, costureira 1)

$\mathrm{N}$ ão sei dizer quanto ganho, depende do trabalho. (Entrevista, costureira 1)

A inda que com certa dificuldade, foi possível verificar que seus rendimentos variam entre um e dois salários mínimos, havendo períodos em que ficam sem trabal ho e sem renda. Também admitem que esse valor não leva em consideração que alguns gastos domésticos aumentaram após ingressarem nesse tipo de trabalho, como a energia elétrica e o tel efone e que, em determinados períodos, contam com 0 trabalho de outras pessoas.

A tualmente minha conta de luz aumentou. A umentaram também gastos com telefone. A pareceram ainda gastos com mecânico de máquinas e peças para a manutenção. (Entrevista, costureira 10)

A lém desses gastos, as faccionistas ainda assumem os prejuízos quanto a eventuais peças confeccionadas que são danificadas. 0 preço do trabalho é determinado pelo tomador de serviços, o que demonstra uma clara hierarquia nas relações entre as costureiras e as fábricas tomadoras do serviço. E ssa situação é típica das cadeias produtivas marcadas pelas assimetrias, decisões unilaterais, fragilidade das relações e pela precarização do trabalho feminino. A situação de busca de menor custo conjugada com menores gastos em obrigações trabal histas, por parte das empresas tomadoras de serviço, fica evidenciada, pois, apesar de não se saber 0 número exato de faccionistas, estas existem em um número próximo ao triplo das empresas de confecções tomadoras. Segundo as faccionistas entrevistadas, é comum uma empresa contratar várias facções para executar o trabalho, e as tentativas de negociação do preço fracassam diante do grande número de costureiras que aceitam trabalhar pelo preço determinado pelo empresário. Nesse sentido, verifica-se que as costureiras domiciliares atuam como um exército industrial de reserva, não apenas em relação às trabalhadoras diretas das confecções, mas, também, em relação às suas companheiras que se encontram na mesma condição. Contudo, o conceito de exército industrial de reserva aplicarse-ia a uma condição provisória para os trabaIhadores, uma vez que a regra seria o trabalho formal. No caso das indústrias de confecção, as costureiras domiciliares estão atuando como exército industrial de reserva permanente, com tendência a tornarem-se a maior parte da mãode-obra desse segmento, cujo trabal ho éutilizado ou dispensado segundo as demandas flexíveis das empresas.

A fragilidade do poder de negociação poderia ser superada através da criação de uma associação de defesa de seus interesses. Contudo, realizando o trabalho de forma isolada, distante de outras companhei ras e dispersas pela cidade, a organização de uma entidade está distante de se concretizar. Sequer conhecem essa possibilidade. A associação em defesa dos interesses coletivos poderia tornar-se um instru- 
mento de val orização profissional, situação que é pouco percebida por essas costureiras, que entendem seu trabalho não como uma possibilidade de profissionalização, mas como contribuição à renda familiar. A desvalorização de seu trabal ho manifesta-se também pelo fato de só poder ser realizado após cumprir as obrigações domésticas, conforme afirmou uma das costureiras:

Com a facção tive a oportunidade de ajudar meu marido nas despesas da casa. Pude ainda ajudar meus filhos a terem acesso a coisas importantes como cursos, por exemplo. Nunca tinha trabal hado antes porque me casei muito nova e tive filhos muito cedo. Não tinha com quem deixar as crianças para trabal har. Como sabia costurar, comecei fazendo pequenos reparos para as vizinhas e hoje sou faccionista. (Entrevista, costureira 9)

A jornada de trabalho das entrevistadas é em média de 12 horas por dia ou enquanto agüentarem, conforme afirmou uma costureira (Entrevista, costureira 6). 0 trabal ho remunerado é intercal ado com as tarefas domésticas e, nas épocas de maior pico produtivo, trabal ham também aos sábados e domingos. Esse prolongamento da jornada de trabalho torna-se vantajoso para os empresários, que não arcam com os tradicionais ônus das horas extras, cujo adicional legal no B rasil é de no mínimo $50 \%$, exigido nas relações assal ariadas reconhecidas. Dessa forma, o trabalho domiciliar, embora mascarado como autônomo, torna-se uma expressão de precariedade, sem a regulamentação das jornadas de trabal ho e outros direitos sociais. M as, apesar das longas jornadas serem prejudiciais à saúde, ao convívio social e ao lazer, as costureiras demonstraram uma certa passividade nessa condição, conforme afirmou uma entrevistada:

Não sei fazer outra coisa a não ser a lida doméstica e costurar. A vantagem é que posso conciliar o trabalho com tarefas domésticas. (Entrevista, costureira 4)

Verifica-se, ao longo das entrevistas, que essas costureiras apresentam algumas rejeições ao trabalho fabril, especialmente quanto à separação entre local de trabal ho e de moradia, pois, além dos salários não serem compensadores, há também a perda de controle sobre seu tempo.

$\mathrm{Na}$ fábrica, até 0 tempo para ir ao banheiro era regulado. Não compensa o salário que recebe para deixar os filhos, as tarefas domésticas e 0 risco de ladrão.

A vantagem é que não tem patrão. $\mathrm{Na}$ fábrica força muito com o trabalho. (Entrevista, costureira 6)

Por outro lado, sentem as desvantagens do trabal ho informal. Algumas queixas das costureiras foram as seguintes:

Se não trabalha não ganha, não têm direitos. A cho ruim esse trabalho porque não tenho nenhum direito. As fábricas deveriam anotar nossa carteira. (Entrevista, costureira 7)

$\mathrm{N}$ ão tem muita vantagem porque não tem carteira anotada. (Entrevista, costureira 3)

A gente trabal ha só na hora do aperto. (Entrevista, costureira 2)

Outra reclamação refere-se à ausência de férias, afirmando algumas costureiras que, quando não estão trabal hando, não significa que estão descansando, pois estão sempre disponíveis para 0 trabal ho e que gostariam de ter férias como os demais trabal hadores.

Essas costureiras, antes de ingressarem no trabal ho domiciliar, trabalhavam em fábricas, mas o trabal ho formal foi abandonado devido à necessidade de cuidar dos filhos, conforme declarou uma entrevistada:

Eu ganhava mais quando não trabal hava por conta própria, mas depois que meus filhos nasceram ficou muito difícil continuar. Então optei pela facção em casa porque posso trabaIhar eficar com el es. (Entrevista, costureira 2)

A inda que a mul her encontre motivos para a realização do trabal ho domiciliar - cuidar dos filhos, da casa ou do marido - , este se constitui como uma forma de inserção excluída da mulher no mercado de trabalho, conforme afirma Posthuma (1998). Trata-se de um trabalho precário, com baixo nível de remuneração, 
ausência de garantias trabal histas e intermitência. M ais que uma opção da mulher, refere-se a um novo patamar de acumulação do capital, marcado pelo retorno de formas mais exacerbadas de exploração do trabalho, típicas das condições da sociedade industrial que antecedeu ao Estado do bem-estar social. Conforme afirma Leite (2004), de um lado, encontra-se 0 empregador, que busca flexibilidade, redução de custos e transferência de riscos, em um contexto de el evada competitividade. De outro, estão as costureiras, mulheres, mães e esposas que acumulam a dupla função: da exclusividade dos cuidados dos afazeres do lar e da contribuição para o seu sustento. Nesse contexto, a indústria da confecção reforça as condições históricas de subordinação da mulher na sociedade, mantendo intacto seu papel de principal responsável pelas tarefas domésticas, ainda que isso Ihe custe um trabalho remunerado precário. 0 papel, culturalmente construído, que a mulher representa na sociedade permite no novo contexto da nova reestruturação produtiva as velhas formas de discriminação e exploração do trabalho.

0 desenvolvimento da indústria da confecção nesta cidade do interior de M inas Gerais, ao longo dos anos 80 e 90, permitiu uma maior inserção da mulher no mercado de trabalho. Contudo, a reestruturação pela qual esse segmento passa faz com que suas trabal hadoras retornem à segregação de suas casas, acumulando tarefas domésticas e trabal ho remunerado precário. Distantes de outras companheiras de trabalho, torna-se difícil para essas mulheres buscar, coletivamente, formas de organização que melhorem suas condições de trabalho. Entretanto, não se trata de um fenômeno exclusivo desse segmento, mas de tendências mais gerais do processo de reestruturação produtiva. N esse sentido, afirma N eves:

D e fato, a utilização da mão-de-obra feminina no processo de flexibilização e modernização produtiva ocorre em meio de jornadas parciais, contratos por tempos determinados, trabal hos em domicílio, utilizando-se uma vez mais da qualificação informal adquirida pel as mul heres no trabal ho doméstico, mas sem nenhuma forma real de valorização do trabal ho feminino. Pelo contrário, elas estão submetidas a condições de trabal ho precárias e inseguras, marcadas por baixos salários, pela realização de várias tarefas simultâneas e flexíveis - ocasionando intensificação do ritmo do trabal ho - e pela perda dos direitos legais. (2000, p. 182)

A expansão do trabalho informal nas indústrias de confecções da cidade tem modificado o perfil da mão-de-obra desse segmento produtivo. A costura, etapa do processo produtivo que ocupa a maior parte do trabal ho, como já foi dito anteriormente, é realizada por mulheres, na informalidade, e tarefas como administração, criação, infesto e corte têm uma maior participação masculina, permanecendo como trabalho formal. M antidas as atuais tendências, os homens devem concentrar-se no topo da cadeia, em tarefas administrativas, de comando, de maior qualificação e, conseqüentemente, com melhor remuneração. $E$ as mulheres permanecerão na ponta da cadeia, realizando o trabalho informal, taylorizado, marcado pela monotonia, repetição e desqualificação.

A reconfiguração de formas de trabalho, nessa nova dinâmica do processo produtivo flexível, demonstrada no processo de trabalho na indústria de confecções, confirma que a adaptação ao risco e à insegurança vem se apresentando como alternativa para a inserção das mulheres no mercado de trabalho. A informalidade nesses novos tempos sinal iza que cada vez mais essa característica do mercado de trabal ho deixa de ser uma situação transitória e passa a ser estrutural. 0 que existe é uma relação sistêmica entre o formal e o informal, uma combinação de diversas formas de trabal ho e de emprego características da flexibilização.

Portanto, o que as pesquisas apontam é a existência de uma forte contradição. Se, por um lado, as mulheres, nestes últimos anos, conquistaram uma maior escolaridade e conseguiram se inserir em postos de trabalho mais qualificados, por outro lado, um grande número ainda permanece em precárias situações, como as empregadas domésticas, e cresce também 0 número de mulheres executando trabalho informal e sem a proteção dos direitos sociais. 
Abstract: The fast-changing process on the global economy in recent years and the productive reestructuration reconfigured gender relations in the labor process. The increasing ingress of women work on the labor market brings at a set of new female life experiences in the place of labor and within the broader context of society, besides turning visible the relations produced in the private sphere. The flexible dynamics of the productive process occasioned, in recent years, a significant growth on informal work, in a process characterized by heterogeneity and also by the systemic form of interaction between formal and informal sectors. The aim of this article is to analyze the work from home jobs realized by women for the confection industry at a medium size city in the state of Minas Gerais (Brazil). The weakening of labor regulation and social rights made possible the proliferation of these precarized activities, generating the flexibilization of labor contract, work conditions, work joumey and an extension/interaction between private/domestic and economic/productive spaces.

Key words: women work; clothing and confection industry, flexible work.

\section{Referências}

A BRA M O, L aís. U m olhar de gênero. Visibilizando precarizações ao longo das cadeias produtivas. In: ABRA M O, L. eABREU, A R. P. (Orgs). Gênero e trabalho na sociologia latino-americana. São Paulo: A last, 1998.

ABREU, Alice de Paiva; SORJ, Bila. Trabalho a domicílio e relações de gênero: as costureiras externas do Rio de J aneiro. In: (Orgs) 0 trabalho invisível: estudos sobre trabalhadores a domicílio no Rio de Janeiro. Rio de Janeiro: Ed. Rio Fundo, 1993.
FUNDAÇÃ O Carlos Chagas. Série mulheres no mercado de trabalho: grandes números. Disponível em: www.fcc.org.br. 1998.

HIRATA, Helena. Reestruturação produtiva, trabalho e relações de gênero. Revista latinoamericana de estudos del trabajo. São Paulo: A last, 1998.

INSTITUTO ETHOS. 0 compromisso das empresas com a valorização da mulher. Disponível em: www.ethos.org.br. 2003.

LEITE, M árcia de Paula. Tecendo a precarização: gênero, trabal ho e emprego na indústria de confecções de São Paulo. A npocs, 2004. [CD-R OM ]

NEVES, M agda deA Imeida. R eestruturação produtiva e estratégias no mundo do trabalho: as conseqüências para os trabalhadores. In: CARVALHO NETO, A ntônio M oreira de; CA RVA L HO, Ricardo A ugusto A lves (Orgs). Sindicalismo e negociação coletiva nos anos 90. B elo Horizonte: Instituto de Relações do Trabalho da PUC M inas, 1998.

Reestruturação produtiva, qualificação e relações de gênero. In: ROCHA, M . I. B. Trabalho e gênero: M udanças, permanências e desafios. São Paulo: Ed. 34, 2000.

; PEDROSA, Célia M aria. 0 trabalho informal feminino na indústria de confecção. In: XXV CON GRESSO - ASOCIACIÓN LATINOAMERICANA DE SOCIOL OGIA (ALA S). Porto A legre, 2005.

POSTHUMA, A nne Caroline. M ercado de trabal ho e exclusão social da força de trabal ho feminina. In: A B RAM O, L. eA BREU, A. R. P. (Orgs). G ênero e trabalho na sociologia latino-americana. São Paulo: A last, 1998.

SILVA, L orena Holzmann da. Trabal ho a domicílio. In: CATTA N I, A. D. (Org.). Trabalho e tecnologia: dicionário crítico. Petrópolis: Vozes, 2004. 
